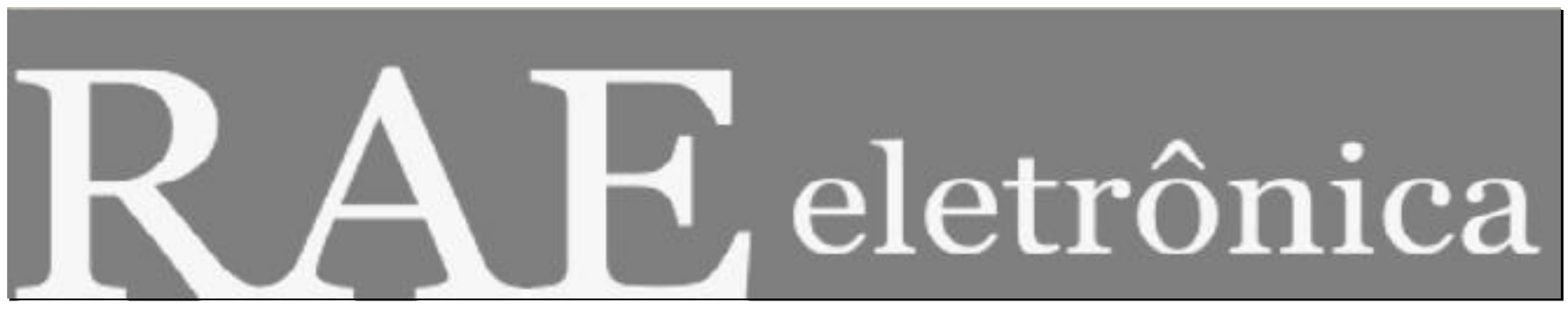

\title{
FORMULAÇÃO DE ESTRATÉGIAS DE DESENVOLVIMENTO BASEADO NO CONHECIMENTO LOCAL
}

Por:

Valdir Fernandes, UFSC

Carlos Alberto Cioce Sampaio, FURB

RAE-eletrônica, v. 5, n. 2, Art. 11, jul./dez. 2006

http://www.rae.com.br/eletronica/index.cfm?FuseAction=Artigo \&ID=3548\&Secao=ARTIGOS \&Volu $\mathrm{me}=5 \&$ Numero $=2 \& \mathrm{Ano}=2006$

(C) Copyright, 2006, RAE-eletrônica. Todos os direitos, inclusive de tradução, são reservados. É permitido citar parte de artigos sem autorização prévia desde que seja identificada a fonte. A reprodução total de artigos é proibida. Os artigos só devem ser usados para uso pessoal e nãocomercial. Em caso de dúvidas, consulte a redação: raeredacao@fgvsp.br.

A RAE-eletrônica é a revista on-line da FGV-EAESP, totalmente aberta e criada com o objetivo de agilizar a veiculação de trabalhos inéditos. Lançada em janeiro de 2002, com perfil acadêmico, é dedicada a professores, pesquisadores e estudantes. Para mais informações consulte o site www.rae.com.br/eletronica.

RAE-eletrônica

ISSN 1676-5648

(C)2006 Fundação Getulio Vargas - Escola de Administração

de Empresas de São Paulo.

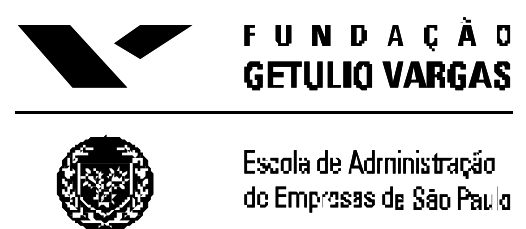


FORMULAÇÃO DE ESTRATÉGIAS DE DESENVOLVIMENTO BASEADO NO CONHECIMENTO LOCAL

Valdir Fernandes - Carlos Alberto Cioce Sampaio

\section{RESUMO}

O planejamento e sua gestão para o ecodesenvolvimento, além de mitigar estratégias concretas de intervenção corretivas, devem também fomentar um novo critério de racionalidade social. A partir desse pressuposto, o objetivo do artigo é analisar experiências de aplicação das metodologias do planejamento estratégico participativo (PEP) e da gestão organizacional estratégica (SiGOS) que promovem o desenvolvimento endógeno. Foram avaliadas sete aplicações conjuntas das metodologias PEP/SiGOS no Estado de Santa Catarina. Em qualquer dos casos predominaram o timbre extraorganizacional (do entorno ao local) e a valorização do conhecimento popular local caracterizado pela capacidade de gerar demandas e propostas que não se distanciam nem se desvinculam das nuances e peculiaridades do quotidiano, a partir do olhar das próprias pessoas. O Estado abre sua atuação para outro ângulo, voltado para a percepção das capacidades e potencialidades locais, a partir de políticas de coordenação e promoção das iniciativas sociais.

\section{PALAVRAS-CHAVES}

Conhecimento local, desenvolvimento local, planejamento, gestão organizacional, participação.

\section{ABSTRACT}

Planning and managing for eco-development in addition to softening intervention procedures also help to generate a new parameter for rationality. This can be demonstrated by the application of PEP (Participative Strategic Planning) and SiGOS (Strategic Organizational Management) as tool for the promotion of endogenous development. Seven experiences of application of both tools were reported in the Brazilian State of Santa Catarina. Findings point out that local knowledge, in the form of accumulation of tacit experiences by the population involved, are seminal for the generation of proposals making up a possible new developmental model. This opens up new roles for the civil society and for a revision of the traditional procedures of the Brazilian public administration, where the state patronizes and centralizes power strengthening bureaucracy and bureaucrats.

\section{KEYWORDS}

Local knowledge, local development, planning, organizational management, participation. 


\section{FORMULAÇÃO DE ESTRATÉGIAS DE DESENVOLVIMENTO BASEADO NO CONHECIMENTO LOCAL \\ Valdir Fernandes - Carlos Alberto Cioce Sampaio}

\section{INTRODUÇÃO}

Atualmente se vive um período de transformações ou pelo menos se espera por elas. O modelo de desenvolvimento atual não consegue mais responder aos novos desafios colocados pela globalização dos circuitos econômicos e culturais. De acordo com Barbieri (1996, p. 12), "o desenvolvimento que significa ato de crescer, progredir, não deve ser entendido, necessariamente, como crescimento ilimitado, uma vez que os ecossistemas possuem seus limites para fornecer a energia a esse crescimento". Isso se confirma ainda, segundo o autor, pela escassez de recursos, de fronteiras para expandir as economias nacionais, de depósitos para armazenar ou eliminar os rejeitos da sociedade industrial e, sobretudo, de acordo com Fernandes e Sant'Anna (2002), de uma política conjunta entre Estado, mercado e sociedade civil para enfrentar os desafios da crise, o que coloca a humanidade diante do desafio de planejar o desenvolvimento humano sem destruir o meio ambiente.

É diante dessa problemática que Sachs (1986) aponta a necessidade de um enfoque de planejamento que promova um modelo de desenvolvimento sustentável também denominado ecodesenvolvimento. Neste trabalho, prefere-se utilizar o termo "ecodesenvolvimento" em virtude da banalização do termo "desenvolvimento sustentável" na literatura especializada. Sob esse enfoque, a ação governamental deve ser descentralizada e participativa, e o Estado tem o papel crucial de ser coordenador do desenvolvimento e das redes de colaboração formadas por empresários, sindicatos, organizações comunitárias, instituições científicas e de informação, que são composições flexíveis de agentes da sociedade civil para uma nova articulação entre Estado e sociedade (Maciel apud Souza $\mathrm{F}^{\mathbf{o}}$, 2002).

Seguindo esse modelo emergem tecnologias sociais baseadas necessariamente em um outro tipo de racionalidade distinta da instrumental, construída a partir da participação e do engajamento da sociedade civil e dos recursos locais, para poder planejar um novo estilo de desenvolvimento por meio de estratégias concretas de intervenção corretivas. Estas devem basear-se em novos critérios de racionalidade social que contenham pelo menos três princípios. Primeiro, a participação, pois aqueles que são afetados por um projeto de desenvolvimento devem participar do seu processo de planejamento, revitalizando assim as funções gestora e fomentadora do Estado, utilizando arranjos institucionais constituídos pelas três esferas de poder - Estado, mercado e sociedade civil. Segundo, o planejamento e a gestão do ecodesenvolvimento baseados em uma metodologia sistêmica e complexa, isto é, não setorial. E, em terceiro lugar, a endogeneidade, que consiste na potencialização dos saberes 


\section{FORMULAÇÃO DE ESTRATÉGIAS DE DESENVOLVIMENTO BASEADO NO CONHECIMENTO LOCAL \\ Valdir Fernandes - Carlos Alberto Cioce Sampaio}

locais, como sendo as tecnologias apropriadas, externalizando seja a dimensão tácita do conhecimento, sejam as interações culturais codificadas (Sampaio, 2004).

A partir desses critérios, pretende-se transformar a sociedade civil em uma terceira esfera de poder que, conjuntamente com as esferas do Estado e do mercado, possa, por meio da aplicação de metodologias de planejamento e de gestão, desencadear em efeito cascata estratégias alternativas de desenvolvimento endógeno de longo prazo. Isso, por sua vez, pode ser compreendido como um componente do ecodesenvolvimento e como um novo critério de racionalidade social.

Partindo-se desses pressupostos, o objetivo central deste trabalho é analisar experiências de aplicações das metodologias de planejamento estratégico participativo (PEP) e gestão organizacional estratégica (SiGOS) que se enquadrem como umas dessas novas tecnologias sociais que visam promover o desenvolvimento endógeno. Espera-se extrair dele lições que permitam sugerir princípios de gestão social que superem a ótica puramente econômica e individualista.

A elaboração de estratégias locais, por meio dessas metodologias de planejamento e gestão participativa, destaca, além do seu componente democrático, a superação da visão tecnicista-conceitual de especialistas, incorporando a visão comunitária e empírica de quem vive na localidade. Isto é, se "empoderam" (empower) as comunidades para que formulem melhor seus problemas e, ao mesmo tempo, os resolvam.

Essa afirmação se baseia principalmente na aplicação das metodologias construtivistas PEP e SiGOS, que foram experimentadas em algumas organizações, localidades, municípios e microbacias hidrográficas, buscando a construção de um conhecimento participativo da realidade e emergindo vocações e potencialidades socioeconômicas e ecológicas. O PEP é uma metodologia desenvolvida pelo pesquisador Souto-Maior Filho e vem sendo aplicada principalmente em organizações de natureza pública. O SiGOS é uma metodologia desenvolvida pelo pesquisador Carlos Alberto Cioce Sampaio e complementa a etapa de implantação de estratégias da maioria das metodologias de planejamento estratégico, sobretudo o PEP.

A centralidade destes trabalhos metodologicamente orientados está em estimular as comunidades locais de modo que elas possam desenvolver novas instâncias de decisão, tais como fóruns ou conselhos comunitários, incrementar atividades de geração de trabalho e renda, e contribuir no manejo dos recursos naturais, inclusive em unidades de conservação que contam com a presença de populações tradicionais.

O eixo central e comum das duas metodologias é o pressuposto de que as pessoas têm potencialidades e que estas podem ser aproveitadas. Em outras palavras, as experiências com as 


\section{FORMULAÇÃO DE ESTRATÉGIAS DE DESENVOLVIMENTO BASEADO NO CONHECIMENTO LOCAL \\ Valdir Fernandes - Carlos Alberto Cioce Sampaio}

metodologias PEP/SiGOS, discutidas neste artigo, exemplificam e demonstram que a extração, sistematização e potencialização do conhecimento popular local possibilitam constituir arranjos institucionais tão necessários para a promoção do desenvolvimento local. Trata-se da utilização do conhecimento surgido de experiências empíricas a partir do viver subjetivo das pessoas e que é utilizado objetivamente no cotidiano delas.

\section{MÉTODO DE PESQUISA}

Este estudo se caracteriza como teórico-empírico em função do tipo de condução epistemológica e metodológica. A pesquisa desenvolvida é predominantemente qualitativa.

A primeira etapa da pesquisa foi iniciada pelos estudos teóricos sobre gestão organizacional estratégica e experiências surgidas da aplicação de planejamentos para um desenvolvimento baseado na endogeneidade local, sobretudo do planejamento estratégico participativo (PEP). A segunda etapa da pesquisa é a avaliação formativa de experiências. A avaliação formativa tem como propósito melhorar ou aperfeiçoar sistemas ou processos (Roesch, 1996). Os dados primários surgiram de observação direta, tanto sistemática como assistemática, e de anotações de campo, na ocasião em que as metodologias foram aplicadas. De maneira complementar, utilizaram-se dados secundários, como tese de doutorado (Sampaio, 1999), relatórios técnicos sobre as experiências (Sampaio, 1997a, 1997b, 1997c, 1997d, 1997e, 1998 e 2000b) e avaliações sobre as oficinas metodológicas feitas pelos participantes. A análise dos dados se baseou predominantemente nas etapas do modelo híbrido das metodologias PEP/SiGOS, conforme apresentado na Figura 1, e nas categorias analíticas participação e conhecimento local. Avaliaram-se sete aplicações conjuntas das metodologias planejamento estratégico participativo (PEP) e gestão organizacional estratégica para o desenvolvimento sustentável (SiGOS) no período compreendido entre 1997 e 2001. Os trabalhos foram coordenados conjuntamente com órgãos do Governo do Estado de Santa Catarina. As especificações dessas experiências estão mais detalhadas no Quadro 1.

\section{DESENVOLVIMENTO ENDÓGENO}




\section{FORMULAÇÃO DE ESTRATÉGIAS DE DESENVOLVIMENTO BASEADO NO CONHECIMENTO LOCAL \\ Valdir Fernandes - Carlos Alberto Cioce Sampaio}

O desenvolvimento endógeno é a capacidade de uma determinada sociedade para adquirir certo domínio sobre o seu desenvolvimento. Isto não implica um controle centralizado governamental, senão por permitir que indivíduos e grupos de indivíduos assumam seu papel de atores do desenvolvimento, negociando interesses individuais e coletivos. A promoção da autonomia de comunidades locais organizadas para que elas tenham gerência efetiva do seu próprio desenvolvimento local é uma das prerrogativas do ecodesenvolvimento. No entanto, não se trata de uma autonomia política com características de movimentos de tipo nacionalista (isolamento) ou autárquico (centralismo e autosuficiência), mas sim de preservar uma identidade local que se concilia com estruturas políticas, institucionais e culturais mais amplas. Em detrimento dessa autonomia e de singularidade local, não se justifica aplicar modelos de desenvolvimento miméticos, de um local para outro, sem antes adaptá-los a cada realidade. O desenvolvimento endógeno estimula, assim, a articulação dos mais diversos segmentos da sociedade local para descobrir as soluções dos principais problemas que são inerentes àquela comunidade (Godard et al., 1987).

Sob essa perspectiva, tanto ambientalistas como governantes assumem que o nível local é o lugar onde efetivamente existem maiores condições para contenção, prevenção e solução da maioria dos problemas ambientais e socioeconômicos. Entretanto, para que essas condições se efetivem é necessário integrar as várias esferas no sentido de construir um debate constante no qual se possa gerar a consciência dos problemas e, ao mesmo tempo, as soluções conjuntas para esses problemas (Fernandes e Sant'Anna, 2002), brindo-se, assim, o pressuposto de que existe na comunidade a potencialidade de conduzir o próprio desenvolvimento: ‘a capacidade de liderar e conduzir o seu próprio desenvolvimento regional, condicionando-o à mobilização dos fatores produtivos disponíveis em sua área e ao seu potencial endógeno, traduz a forma de desenvolvimento denominado endógeno" (Souza Fo., 2002, p. 2).

\section{PROCESSO DE TOMADA DE DECISÃO}

O processo de tomada de decisão sugere a perspectiva da escolha. As escolhas se ajustam entre oportunidades (externas e objetivas) e desejos (internos e subjetivos), isto é, o que as pessoas podem fazer e o que elas querem fazer. Em outras palavras, ela é mediada entre as liberdades positiva e negativa (Peci, 2003). Nesse sentido, não importa se a organização está no âmbito de uma localidade, de um município, microrregião, bacia hidrográfica, região ou outro espaço qualquer, o planejamento e a 


\section{FORMULAÇÃO DE ESTRATÉGIAS DE DESENVOLVIMENTO BASEADO NO CONHECIMENTO LOCAL \\ Valdir Fernandes - Carlos Alberto Cioce Sampaio}

gestão organizacional implicam sempre um conjunto de etapas pedagógicas, isto é, metodologias ou tecnologias sociais para facilitar a tomada de decisão. As metodologias de tomada de decisão podem ser sistematizadas em etapas, tais como elaboração, implementação e avaliação. A etapa de elaboração consiste em formular os problemas mais importantes para a organização, partindo da relação entre vocação organizacional (missão) e análise ambiental, ou seja, a identificação dos problemas organizacionais mais importantes, chamados de questões estratégicas. A etapa de implementação consiste na identificação das soluções das questões estratégicas (ações estratégicas), e a etapa de avaliação consiste no monitoramento das soluções implementadas (Sampaio, 2000a).

As etapas do processo de tomada de decisão organizacional são conduzidas por meio da ação social denominada racionalidade. A racionalidade é uma qualidade do pensamento humano e do comportamento que resulta da adaptação da razão, isto é, a capacidade de pensar de maneira ordenada e lógica. Entretanto, a racionalidade não está isenta de contradição, ou seja, ela pode ter um componente ilógico quando se sobrepõem interesses pessoais sobre sociais. A racionalidade é sempre um atributo individual, mas não é isolado do coletivo (Souto-Maior, 1998; Sampaio, 2000a). Vale lembrar Hegel que afirma: "a realidade humana só pode ser social: é preciso, ao menos, ser dois para ser humano" (Chanlat, 1998, p. 10).

A racionalidade significa adesão do indivíduo a um conjunto de valores incorporados no senso comum (coletivo) que, por sua vez, não pode ser especificado principalmente por conter componente valorativo (tácito). Toda vez que um indivíduo escolhe uma norma de ação em lugar de outra está se ordenando a partir de uma lógica, muitas vezes baseado no coletivo. Portanto, não existem interesses sociais independentes dos interesses individuais de seus membros.

A racionalidade pode ser sistematizada em tipologias, quais sejam: utilitarista econômica, baseada em cálculo de ganhos individuais de curto prazo; utilitária coletiva, baseada em cálculo de conseqüências coletivas; e substantiva, baseada em valores (inclusive tradições), e não em cálculos. Esta última é uma racionalidade atrelada à ética na razão, à intersubjetividade e à emancipação humana. Há também a chamada extra-racionalidade, podendo ser considerada como uma préracionalidade, baseada em um conhecimento tácito, ou seja, ainda pouco visível (Weber, 1947; Ramos, 1981; Hobbes, 1979; Souto-Maior, 1988).

O conhecimento tácito, também denominado extra-racional, é um conhecimento de difícil mensuração racional que, mesmo assim, não pode ser considerado como irracional. A dimensão tácita do conhecimento pode estar vinculada no âmbito da subjetividade coletiva. Tem-se a percepção de que se trata de um conhecimento que se compartilha no âmbito local, nos simbolismos do saber local. 


\section{FORMULAÇÃO DE ESTRATÉGIAS DE DESENVOLVIMENTO BASEADO NO CONHECIMENTO LOCAL \\ Valdir Fernandes - Carlos Alberto Cioce Sampaio}

Negar o subjetivo é negar as diferenças, a individualidade do próprio homem. Assim, o conhecimento extraído do saber local, e de algum modo contendo o conhecimento tácito, gera subsídios para a formulação de políticas públicas relacionadas à realidade e que conseqüentemente solucionam os problemas mais importantes do mundo da vida (Tuan, 1980; Polany, 1983; Souto-Maior, 1988; MaxNeef, 1993).

As tipologias de racionalidade mencionadas anteriormente podem variar entre os dois extremos, da objetividade à subjetividade. De certo modo, sem grande rigor, a objetividade se relaciona à racionalidade organizacional, isto é, quanto uma idéia é aceita por um grupo organizado, enquanto a subjetividade está relacionada a uma pré-racionalidade organizacional, ou seja, quando uma idéia ainda não é aceita por uma organização. A objetividade é atrelada ao mundo da realidade, dos fatos, e a subjetividade é atrelada ao mundo das idéias ou, ainda, ao mundo dos sentimentos. Entre o ato de idealizar e o ato de agir há diferenças significativas. O mundo das idéias é muito diferente do mundo das ações porque o que pode ser dito nem sempre pode ser realizado. Além disso, há diferenças tanto nos sistemas de produção de idéias e ações quanto na velocidade com que as idéias e as ações são produzidas, isto é, as idéias podem desaparecer e mudar mais rapidamente do que as ações (Brunsson, 1994; Goleman, 2003).

\section{METODOLOGIAS PARTICIPATIVAS DE PLANEJAMENTO E DE GESTÃO (PEP E SiGOS)}

Um dos pressupostos do desenvolvimento endógeno e também das duas metodologias aqui analisadas consiste na participação da sociedade civil em seu processo de planejamento e de gestão, revelando o conhecimento e as capacidades locais. A participação pode e deve ser orientada para transformar boas idéias em ações efetivas, portanto não faz sentido fomentar a participação comunitária se não se visualizar uma ação efetiva da comunidade nas decisões de matérias que lhe digam respeito. Ou seja, aqueles que são afetados por um projeto de desenvolvimento devem participar do seu processo de planejamento, tornando o planejamento participativo uma forma de intervir na realidade, ou seja, uma forma que passa por três momentos cruciais: a autocrítica, o diálogo aberto e a ação dos interessados (Demo, 1993; Dowbor, 1987; Tragtemberg, 1987; Scherer-Warren, 1993; Gondim, 1988; Senge, 2001).

O planejamento e a gestão participativa acabam conduzindo a resultados que extrapolam o âmbito espacial da organização coordenadora do processo. Por exemplo, participantes de oficinas de planejamento e gestão organizacional de um município devem relevar os impactos das ações 


\section{FORMULAÇÃO DE ESTRATÉGIAS DE DESENVOLVIMENTO BASEADO NO CONHECIMENTO LOCAL \\ Valdir Fernandes - Carlos Alberto Cioce Sampaio}

estratégicas que podem causar em municípios vizinhos. Essa mudança de enfoque organizacional para o enfoque interorganizacional torna-se imperativa quando se releva o entorno territorial organizacional, ou seja, a perspectiva extra-organizacional (Sampaio, 1996). Nesse sentido, duas metodologias, que serão descritas a seguir, vêm sendo aplicadas, sobretudo em organizações públicas de municípios e microrregiões e em organizações chamadas do terceiro setor, como os movimentos associativistas.

A primeira metodologia consiste no planejamento estratégico participativo (PEP). O PEP é uma metodologia de planejamento estratégico, elaborada participativamente, na qual são desenvolvidas técnicas de trabalho em equipe, estimulando a dinâmica de grupo e, ao mesmo tempo, construindo a sua singularidade organizacional e espacial, de modo que possam emergir estratégias (Souto-Maior, 1994). Estratégia, por sua vez, é o tempo de resposta organizacional ao seu ambiente, é a capacidade de antecipar o futuro ou, ainda, é a capacidade de criar compatibilidade e integração com o meio ambiente organizacional (Porter, 1991, 1999; Mintzberg, 1987, 2001; Wall e Wall, 1996; Wilson, 1990).

A segunda metodologia consiste na gestão organizacional estratégica para o desenvolvimento sustentável (SiGOS). O SiGOS é uma metodologia de gerenciamento de estratégias que sistematiza todo o processo de implantação e monitoramento de ações necessárias que promovam o ecodesenvolvimento (Sampaio, 2000a). As duas metodologias buscam construir, por meio de oficinas com os participantes, o conhecimento local sobre a organização e os possíveis impactos que poderiam causar a seu entorno. De maneira geral, pode-se apontar que o PEP centra-se na elaboração de estratégias, enquanto o SiGOS focaliza a implantação e avaliação de estratégias, como ilustra a Figura 1.

A metodologia PEP e SiGOS é iniciada a partir da delimitação do espaço territorial e microrregional que compõem o arranjo institucional constituído e da identificação das organizações e de suas respectivas relações que compõem tal arranjo (Etapa 1). Esclarecem-se o ideário e a vocação organizacional com ênfase interorganizacional (Etapa 2), analisando-se o ambiente externo oportunidades e ameaças, caracterizadas por fatores que influenciam a organização, sendo que o inverso nem sempre é verdadeiro - e o ambiente interno, fatores que são controlados pela organização (Etapa 3). E, por fim, identificam-se os problemas organizacionais mais importantes (Etapa 4 Questões Estratégicas).

Em seguida, aplica-se a etapa "ação estratégica", que tem como finalidade desenvolver soluções referenciais para os problemas essenciais da organização. Essa etapa decompõe-se em: propostas sonhadoras, que são aquelas que solucionam as questões estratégicas; obstáculos, que são aqueles que 
impedem que as propostas sonhadoras se concretizem; e ações concretas, que são aquelas que removem os obstáculos às propostas sonhadoras (Etapa 5).

\section{FIGURA 1 - Metodologia PEP e SigOS}

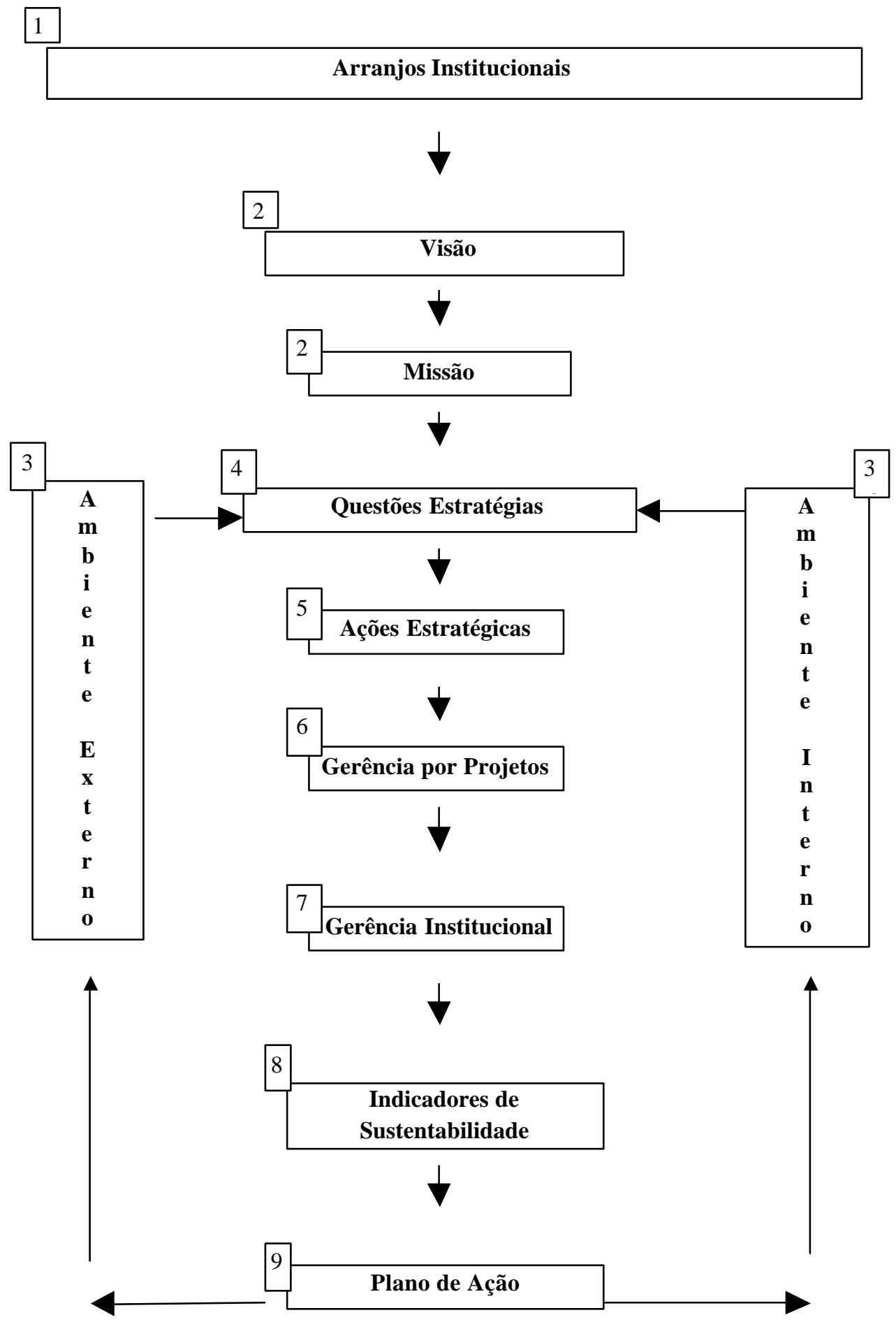

Fonte: Sampaio (1999). 


\section{FORMULAÇÃO DE ESTRATÉGIAS DE DESENVOLVIMENTO BASEADO NO CONHECIMENTO LOCAL \\ Valdir Fernandes - Carlos Alberto Cioce Sampaio}

A seguir, reagrupam as ações estratégicas em projetos estratégicos. A "gerência por projetos" é uma ferramenta organizacional e interorganizacional que se utiliza de uma estrutura matricial para implantar e monitorar sistematicamente um conjunto de ações facilitadoras e seus respectivos responsáveis, ou seja, o projeto. Pela complexidade dessa estrutura, os projetos são muito bem detalhados e prevêem todos os passos, incluindo nome do projeto, objetivo, justificativas, o coordenador do projeto, critérios avaliativos e metas, prazo inicial e de término, orçamento por fonte de recurso e ações facilitadoras que compõem o projeto (Etapa 6 - Projetos Estratégicos).

Em seguida, aplica-se a etapa "gerência institucional", que é uma metodologia organizacional de ênfase interorganizacional, valendo-se de uma estrutura matricial para implantar e monitorar sistematicamente um conjunto de projetos e seus respectivos coordenadores, ou seja, o plano como um todo. A gerência institucional se divide em quatro subetapas: a "avaliação de performance", que tem como objetivo avaliar os projetos e todas as suas ações facilitadoras, utilizando-se de critérios avaliadores que sugerem um indicador de performance, ou melhor, uma meta; o "sistema de informações gerenciais" (SIG), que tem a finalidade de organizar por computador, ou até mesmo manualmente, todos os dados de um determinado sistema de informações operacionais e, por sua vez, transformá-los em gerenciáveis; a "política de recompensa", que tem como prioridade estimular e motivar os coordenadores, responsáveis e a equipe de trabalho dos projetos de modo que as metas possam ser viavelmente atingidas; e o "plano de comunicação", que delineia e direciona as estratégias de comunicação de uma organização, tendo como finalidade principal institucionalizar a imagem da organização/interorganização (Etapa 7).

Logo depois, aplica-se a etapa "indicadores de sustentabilidade”, que identifica critérios de efetividade de uma organização em relação ao seu entorno. Esses critérios são estabelecidos pela própria organização de maneira que se permita avaliar a eficiência dos seus processos, bem como a eficácia dos resultados alcançados ou sua contribuição para o bem-estar da população. Para demonstrar graficamente a performance de projetos, sugere-se a representação em polígono regular (Etapa 8). E, finalmente, sugere-se um plano de ação que priorize as ações de curto prazo, parametrizadas pelas ações de médio e longo prazos, cujo objetivo é oxigenar todo o plano (Etapa 9).

\section{EXPERIÊNCIAS DE PEP E SiGOS}


Entre os anos 1997 e 2001 as metodologias PEP e SiGOS foram aplicadas conjuntamente em três associações de municípios, em um município em dois mandatos diferentes, em uma federação de municípios, em uma organização não governamental (ONG) e em um fórum local. As experiências realizadas com a proposta híbrida do modelo PEP/SiGOS estão expostas e analisadas em relatórios técnicos (Sampaio, 1997a, 1997b, 1997c, 1997d, 1997e, 1998, 2000b). Com base nesses relatórios se apresentam alguns extratos dessas experiências no Quadro 1

\section{QUADRO 1 - Experiências de PEPp/SiGOS implementadas entre 1997 e 2001}

\begin{tabular}{|c|c|c|c|c|c|}
\hline Oficina & $\begin{array}{l}\text { Organizaçã } \\
\text { o-Líder }\end{array}$ & Organizações/Entidades & Local & Data & Coordenação \\
\hline $\begin{array}{l}\text { 4.1 Curso de Gestão } \\
\text { Institucional de } \\
\text { Projetos Estratégicos } \\
\text { Workshop de } \\
\text { Gestão Estratégica } \\
\text { de Arranjos } \\
\text { Institucionais para o } \\
\text { Desenvolvimento } \\
\text { Sustentável do } \\
\text { município de São } \\
\text { José do Cerrito (SC) }\end{array}$ & Fórum Local & $\begin{array}{l}\text { Cepagro e EpagriI } \\
\text { Cepagro; Instituto Vianei; associações } \\
\text { de moradores; CDL; Sindicato dos } \\
\text { Trabalhadores Rurais }\end{array}$ & \begin{tabular}{|l} 
Florianópolis \\
São José do \\
Cerrito
\end{tabular} & $\begin{array}{l}1^{\circ} \text { semestre de } \\
1997\end{array}$ & $\begin{array}{l}\text { Carlos Alberto Cioce } \\
\text { Sampaio, assistido } \\
\text { por Valdir } \\
\text { Fernandes }\end{array}$ \\
\hline $\begin{array}{l}\text { 4.2 Programa de } \\
\text { Modernização das } \\
\text { Associações de } \\
\text { Municípios de Santa } \\
\text { Catarina }\end{array}$ & $\begin{array}{l}\text { SDM-SC e } \\
\text { Fecam }\end{array}$ & $\begin{array}{l}\text { SDM; Fecam e todas as associações de } \\
\text { municípios }\end{array}$ & $\begin{array}{l}\text { Florianópolis, } \\
\text { Balneário } \\
\text { Camboriú; } \\
\text { Lages; Chapecó }\end{array}$ & \begin{tabular}{|l}
$1^{\circ}$ e $2^{\circ}$ \\
semestres de \\
1997
\end{tabular} & $\begin{array}{l}\text { Carlos Alberto } \\
\text { Cioce Sampaio }\end{array}$ \\
\hline $\begin{array}{l}\text { Projeto de } \\
\text { Modernização } \\
\text { Administrativa da } \\
\text { Associação de } \\
\text { Municípios do } \\
\text { Extremo Sul } \\
\text { Catarinense - } \\
\text { Amesc }\end{array}$ & Ames & $\begin{array}{l}\text { Prefeituras de municípios que compõem } \\
\text { a Amesc: Araranguá, Santa Rosa de } \\
\text { Lima, São João do Sul, Sombrio, } \\
\text { Balneário Arroio do Silva, Balneário } \\
\text { Gaivota, Ermo, Jacinto Machado, } \\
\text { Maracajá, Meleiro, Morro Grande, } \\
\text { Passo de Torres, Timbé do Sul, Turvo e } \\
\text { Praia Grande }\end{array}$ & Araranguá & $\begin{array}{l}2^{\circ} \text { semestre } \\
\text { de } 1997\end{array}$ & $\begin{array}{l}\text { Carlos Alberto Cioce } \\
\text { Sampaio, assistido } \\
\text { por Valdir } \\
\text { Fernandes }\end{array}$ \\
\hline $\begin{array}{l}\text { Projeto de } \\
\text { Modernização } \\
\text { Administrativa da }\end{array}$ & Ammoc & $\begin{array}{l}\text { Prefeituras de municípios que compõem } \\
\text { a Ammoc: Joaçaba, Lacerdópolis, } \\
\text { Luzerna, Ouro, Tangará, Treze Tílias, }\end{array}$ & $\begin{array}{l}\text { Joaçaba e } \\
\text { Treze Tílias }\end{array}$ & $\begin{array}{l}2^{\circ} \text { semestre } \\
\text { de } 1997\end{array}$ & $\begin{array}{l}\text { Carlos Alberto Cioce } \\
\text { Sampaio, assistido } \\
\text { por Valdir }\end{array}$ \\
\hline
\end{tabular}




\begin{tabular}{|c|c|c|c|c|c|}
\hline $\begin{array}{l}\text { Associação de } \\
\text { Municípios do } \\
\text { Meio-Oeste } \\
\text { Catarinense - } \\
\text { Ammoc }\end{array}$ & & $\begin{array}{l}\text { Vargem Bonita, Jaborá, Herval do } \\
\text { Oeste, Erval Velho, Água Doce, } \\
\text { Catanduvas, Capinzal e Ibicaré }\end{array}$ & & & Fernandes \\
\hline $\begin{array}{l}\text { Projeto de } \\
\text { Modernização } \\
\text { Administrativa da } \\
\text { Associação de } \\
\text { Municípios da } \\
\text { Região Serrana } \\
\text { Catarinense - } \\
\text { Amures }\end{array}$ & Amures & $\begin{array}{l}\text { Lages, Anita Garibaldi, Bacaina do Sul, } \\
\text { Bom Jardim da Serra, Bom Retiro, } \\
\text { Campo do Sul, Capão Alto, Cerro } \\
\text { Negro, Correia Pinto, Otacílio Costa, } \\
\text { Painel, Palmeira, Ponte Alta, Rio } \\
\text { Rufino, São Joaquim, São José do } \\
\text { Cerrito, Urubici e Urupema }\end{array}$ & Lages & $\begin{array}{l}1^{\circ} \text { semestre } \\
\text { de } 1998\end{array}$ & $\begin{array}{l}\text { Carlos Alberto } \\
\text { Cioce Sampaio }\end{array}$ \\
\hline $\begin{array}{l}\text { 4.3 Planejamento } \\
\text { Estratégico } \\
\text { Participativo e } \\
\text { Gestão } \\
\text { Organizacional } \\
\text { Estratégica para a } \\
\text { Prefeitura } \\
\text { Municipal de } \\
\text { Gaspar - SC } \\
\text { Análise Ambiental } \\
\text { do município de } \\
\text { Gaspar }\end{array}$ & $\begin{array}{l}\text { Prefeitura } \\
\text { Municipal } \\
\text { de Gaspar } \\
\text { Prefeitura } \\
\text { Municipal } \\
\text { de Gaspar }\end{array}$ & $\begin{array}{l}\text { Prefeitura municipal (prefeito municipal } \\
\text { e todas as secretarias de governo), } \\
\text { Caixa Econômica Federal, CDL, } \\
\text { Serviço Autônomo Municipal de Água } \\
\text { e Esgoto (Samae) } \\
\text { Prefeitura municipal (prefeito municipal } \\
\text { e todas as secretarias de governo) e } 27 \\
\text { associações de moradores }\end{array}$ & Gaspar & $\begin{array}{l}1^{\mathrm{o}} \text { semestre de } \\
2000\end{array}$ & $\begin{array}{l}\text { Carlos Alberto Cioce } \\
\text { Sampaio, assistido } \\
\text { por Valdir } \\
\text { Fernandes }\end{array}$ \\
\hline
\end{tabular}

Fonte: Sampaio (1997a, 1997 b, 1997c, 1997d, 1997e, 1998 e 2000b).

\section{Curso de Gestão Institucional de Projetos Estratégicos e Workshop de Gestão Estratégica de} Arranjos Institucionais para o Desenvolvimento Sustentável do município de São José do Cerrito (SC)

O primeiro convênio firmado foi com o Projeto Novas Fronteiras do Cooperativismo, ligado ao Programa de Desenvolvimento das Nações Unidas (PNUD), coordenado pelo Centro de Estudos e Promoção da Agricultura de Grupo (Cepagro) para realizar um curso no mês de junho de 1997. Segundo o folder do projeto, o objetivo do curso era ministrar uma disciplina denominada Gestão Institucional de Projetos Estratégicos, enfocando a importância da operacionalização de planos de desenvolvimento local sustentável para agrônomos e extensionistas rurais do Cepagro e da Empresa de Pesquisa Agropecuária de Santa Catarina (Epagri). As falhas desse curso foram muitas, conforme se 
FORMULAÇÃO DE ESTRATÉGIAS DE DESENVOLVIMENTO BASEADO NO CONHECIMENTO LOCAL

Valdir Fernandes - Carlos Alberto Cioce Sampaio

verificou na avaliação dos participantes do projeto, como ausência de um módulo prático que pudesse visualizar as etapas de implementação e avaliação do modelo híbrido PEP/SiGOS: Etapa 6 (gestão por projetos), Etapa 7 (gestão institucional), Etapa 8 (indicadores de sustentabilidade) e Etapa 9 (plano de ação). A pedagogia do curso se baseou em módulos puramente conceituais e acabou não revelando a prática acumulada de aplicação de metodologias de planejamento e de gestão do coordenador do projeto, sobretudo como membro da equipe da Associação de Profissionais para a Promoção do Planejamento Estratégico e Participativo (Apep). Talvez este seja um exemplo da dificuldade de transformar a dimensão tácita do conhecimento adquirido por meio de experiências subjetivas em conceitos racionalizados quando não se utilizam exemplos visíveis.

Contudo, as lições foram maiores ainda. Entre elas, concluiu-se que não era boa prática induzir os participantes a formularem ações estratégicas (Etapa 5) que se enquadrassem previamente nas dimensões ecológica e socioeconômica do desenvolvimento sustentável. Devido à pouca compreensão dos participantes sobre tais dimensões, era necessário intervir muitas vezes para aclarar as dúvidas surgidas nas oficinas comunitárias, prejudicando a dinâmica do processo participativo. Uma alternativa foi aplicar seminários que tratassem das tais dimensões do desenvolvimento de modo que elas pudessem emergir voluntariamente a partir das oficinas comunitárias, ao invés de serem induzidas pelo coordenador do projeto.

O segundo convênio originou o workshop intitulado Gestão Estratégica de Arranjos Institucionais para o Desenvolvimento Sustentável, integrando o Plano de Desenvolvimento Local do município de São José do Cerrito (SC), coordenado pelo Centro de Estudos e Promoção da Agricultura de Grupo (Cepagro) e pelo Centro Vianei de Educação Popular em agosto de 1997. Segundo o Plano de Desenvolvimento Local do município de São José do Cerrito, esse workshop de gestão complementou um Planejamento Estratégico Participativo (PEP) realizado neste município, implementado, porém, pela própria Cepagro e pelo Centro Vianei, na qual se originou o Fórum de Desenvolvimento Local do Município. O PEP de São José do Cerrito propôs inicialmente quatro projetos estratégicos: meio rural, saúde, educação e fórum de desenvolvimento. O workshop de gestão foi iniciado a partir da Etapa 7 (projetos estratégicos) da metodologia PEP/SiGOS. Como resultado do workshop, esses projetos anteriormente propostos foram hierarquizados, readequados e complementados. Constatou-se ainda a necessidade de se criar uma organização privada sem fins lucrativos que, em parceria com a prefeitura municipal, possibilitaria a coordenação do Projeto Fórum de Desenvolvimento. O fórum, por sua vez, coordenaria os três outros projetos - meio rural, saúde, educação - e ainda outro surgido posteriormente sob a denominação "social". Cabe destacar que a 
FORMULAÇÃo DE ESTRATÉGIAS DE DESENVOLVIMENTO BASEADO NO CONHECIMENTO LOCAL

Valdir Fernandes - Carlos Alberto Cioce Sampaio

constituição do fórum asseguraria às lideranças, surgidas ou ratificadas a partir do workshop, participação maior no processo de desenvolvimento local. A perspectiva da participação direta das lideranças comunitárias em todas as etapas do planejamento, elaboração (Etapa 1 até Etapa 5), implementação (Etapas 6 e 9) e avaliação (Etapas 7 e 8) privilegiou o conhecimento popular sobre os problemas comunitários e suas possíveis soluções ao invés de privilegiar o conhecimento tecnicista.

\section{Programa de Modernização das Associações de Municípios de Santa Catarina}

O terceiro convênio foi o Programa de Modernização das Associações de Municípios de Santa Catarina, sob a coordenação geral da Gerência Institucional da Secretaria Estadual de Desenvolvimento Urbano e Meio Ambiente (SDM) e sob a coordenação metodológica da Associação de Profissionais para a Promoção do Planejamento Estratégico e Participativo (Apep). Entre os meses de junho de 1997 e março de 1998, essas entidades desenvolveram quatro workshops. Segundo Perotto (1996), o objetivo dos workshops foi reorganizar regionalmente o associativismo municipal de modo que pudesse incrementar o desenvolvimento das microrregiões e, conseqüentemente, do Estado de Santa Catarina.

O primeiro workshop dos quatro realizados foi o Programa de Modernização Administrativa da Federação Catarinense de Municípios (Fecam), envolvendo a maioria das 19 associações de municípios do Estado. Essas reuniões de trabalho foram realizadas em etapas progressivas, conforme sugere a metodologia PEP/SiGOS. Todas as nove etapas da metodologia foram implementadas na íntegra com a participação efetiva dos secretários executivos, cargo equivalente ao de gerente das associações, e, eventualmente, de alguns de seus assessores. Os presidentes das associações, cargos políticos ocupados por prefeitos dos municípios que compõem cada associação, participaram na primeira, segunda e última etapa da metodologia, nas quais se ratificaram o compromisso com o arranjo institucionalizado, determinando a visão e a missão organizacional e apresentando o plano de ação de modernização da Fecam. Inclusive, nesta última etapa, participaram deputados estaduais e servidores dos primeiros escalões do governo estadual. Vale observar que as pessoas que ocupam cargos de secretários executivos nas associações municipais são geralmente funcionários técnicos de carreira, porém atuando comunitariamente por longos anos de serviços prestados nas associações e conhecedores das práticas políticas e administrativas municipais e de seus enlaces com outras instâncias públicas.

Os demais workshops, dos Projetos de Modernização Administrativa da Associação de Municípios do Extremo Sul Catarinense (Amesc), do Meio-Oeste Catarinense (Ammoc) e da Região Serrana Amures), foram realizados concomitantemente com o workshop da Fecam, por ser esta a 
FORMULAÇÃO DE ESTRATÉGIAS DE DESENVOLVIMENTO BASEADO NO CONHECIMENTO LOCAL

Valdir Fernandes - Carlos Alberto Cioce Sampaio

federação que representa as associações municipais. Segundo os relatórios técnicos, as lições nesse período de oito meses do Programa de Modernização das Associações foram muitas. Entre essas lições se destacam as seguintes: delimitar o espaço territorial de atuação interorganizacional (Etapa 1 organizações e seus enlaces microrregionais) e determinar a visão e missão organizacionais (Etapa 2), contando com a participação imprescindível dos principais decisores (prefeitos municipais). Nas demais etapas, ditas mais operacionais, os demais decisores, aliás, aqueles que conhecem o cotidiano organizacional, prosseguem participando; na Etapa 7 (gerência institucional) cria-se uma estrutura virtual ou física que coordene todos os projetos estratégicos (Etapa 6). Em quase todas as oficinas realizadas nas associações foi necessário dar origem a um novo departamento, como se verificou no workshop de São José do Cerrito, com a criação de uma organização privada sem fins lucrativos. Ao longo da implementação dos workshops é conveniente informar de forma clara e sintética a comunidade local, inclusive valendo-se de inserções publicitárias em meios de comunicação. A Etapa 8 (indicadores de sustentabilidade) é o termômetro de efetividade interorganizacional e extraorganizacional. Aqui são avaliadas as próprias organizações que compõem o arranjo institucional, verificando-se os benefícios para as prefeituras que compõem a associação municipal. Também se avalia se o arranjo institucional está sendo efetivo para seu entorno territorial, verificando-se se a população que compõe a microrregião está sendo beneficiada.

As experiências que tiveram maior participação de membros engajados de organizações que compunham a interorganização foram as que mais possibilitaram a emersão do conhecimento popular local, presumidamente com dimensões tácitas, a respeito do cotidiano organizacional e interorganizacional. Isso implica dizer que quanto maior a participação de membros engajados, maior será a chance do aparecimento de relações informais (entranhas organizacionais) com suas implicações organizacionais e interorganizacionais.

\section{Planejamento Estratégico Participativo e Gestão Organizacional Estratégica para a Prefeitura Municipal de Gaspar - SC}

O planejamento e sua gestão realizados no município de Gaspar englobaram dois momentos. No primeiro deles, em março de 2000, foi realizado um workshop envolvendo principalmente membros do governo municipal, recém-empossados, logo após a alteração do colegiado em fim de mandato. Nesse workshop foram aplicadas as primeiras seis etapas da metodologia PEP/SiGOS, ou seja, da identificação dos arranjos institucionais até a gestão por projetos, aproveitando um trabalho 
FORMULAÇÃO DE ESTRATÉGIAS DE DESENVOLVIMENTO BASEADO NO CONHECIMENTO LOCAL

Valdir Fernandes - Carlos Alberto Cioce Sampaio

anteriormente realizado que apontava as demandas das associações de moradores de bairros identificadas por elas próprias. Após o término do workshop, ficou evidenciado que o planejamento e sua gestão realizados poderiam subsidiar a proposta de plano de governo de uma candidatura que estava se articulando no âmbito de uma dissidência de coligação partidária do até então governo municipal. Todavia, essa chapa não se elegeu posteriormente, o que fez pensar que o planejamento participativo municipal, predominante comunitário, isto é, baseado no conhecimento popular local, tornar-se-ia legítimo mesmo para qualquer legislatura municipal, independentemente das coligações partidárias. Entretanto, não é tarefa fácil explicar aos novos mandatários a desvinculação partidária de trabalhos comunitários anteriormente realizados.

No segundo momento, em fevereiro de 2001, foi realizado um workshop envolvendo principalmente dirigentes de associações de moradores de bairros, no qual foi elaborado um diagnóstico do município que serviria para subsidiar uma proposta de orçamento participativo da equipe de governo recém-empossada. Nesse workshop foram aplicadas as primeiras quatro etapas da metodologia PEP/SiGOS, ou seja, desde a identificação dos arranjos institucionais até as questões estratégicas. Na mesma ocasião, membros da equipe de governo produziram paralelamente outro diagnóstico municipal. Partindo da avaliação dos participantes, constatourse que a participação comunitária produziu um diagnóstico do ambiente interno (Etapa 3 - pontos fortes e fracos) mais conectado com as reais potencialidades e debilidades municipais, comparado com o grupo da equipe de governo. Entretanto, não transpareceu o mesmo quando se analisou o ambiente externo, Etapa 3, porque o grupo da equipe de governo produziu uma análise ambiental externa mais consistente, em comparação com o grupo comunitário, o que não implica que o trabalho de um grupo desqualificou o outro; pelo contrário, os dois trabalhos grupais se complementaram.

\section{CONSIDERAÇÕES FINAIS}

As oficinas quase sempre contaram com a participação de representantes de setores da sociedade local. Participaram tanto pessoas de origem humilde, das comunidades - muitas das quais sem qualquer formação escolar, que ofereceram ao processo um forte componente de empirismo -, quanto pessoas com nível de formação acadêmica e política, como técnicos de nível superior, professores, secretários municipais e prefeitos. 
FORMULAÇÃO DE ESTRATÉGIAS DE DESENVOLVIMENTO BASEADO NO CONHECIMENTO LOCAL

Valdir Fernandes - Carlos Alberto Cioce Sampaio

Em quaisquer dos casos predominaram o timbre extra-organizacional (consideração do entorno territorial na gestão organizacional) e a valorização do conhecimento local popular caracterizado pela capacidade de gerar demandas e propostas, que não se distanciavam nem se desvinculavam das nuances e peculiaridades do quotidiano a partir do olhar dos próprios atores.

Essa capacidade está potencializada principalmente a partir do conhecimento empírico, supondo que contém conhecimento extra-racional da realidade retido pelos atores locais, a qual revela não só os problemas como também as próprias soluções. O destaque dado aqui a esse conhecimento contraria, concordando com Santos (2000), a concepção de conhecimento moderno. Este, por sua vez, é pautado em um modelo globaltotalitário que nega o caráter racional de todas as outras formas de conhecimento que não se fundamentem nos seus princípios epistemológicos e nas suas regras metodológicas, onde o homem é consagrado enquanto sujeito epistêmico, mas não como sujeito empírico.

Trata-se de um conhecimento que os atores constroem a partir da percepção particular de sua realidade, trazendo à tona aspectos e peculiaridades muitas vezes não acessíveis aos pesquisadores externos. Ao mesmo tempo, a partir da valorização desses atores e do resgate da sua identidade constrói-se um novo tipo de cidadania baseada na participação engajada.

Todavia, não se pretende considerar o modelo híbrid o PEP/SiGOS como acabado. Como é um modelo flexível, espera-se que complemente outras abordagens, mesmo porque ele surgiu exatamente de outras já experimentadas. Tal modéstia é justificada também por um paradoxo que o transforma em uma metodologia eternamente inacabada. Por um lado, é um modelo incipiente com limitações que, ao longo de muitas experimentações empíricas, vai se consolidando como uma abordagem mais lapidada e, por outro, possui uma característica de adaptabilidade, originada, sobretudo, pelo processo participativo que se sugere em suas etapas, isto é, não se faz necessário aplicar todas as nove etapas do modelo PEP/SiGOS, mesmo porque se sugere sempre relevar as experiências anteriores realizadas de modo que não transpareça a idéia de trabalho perdido aos membros que participaram de oficinas metodológicas passadas.

A justificativa que considera o PEP/SiGOS como uma metodologia eternamente inacabada é baseada sobretudo na aplicação das metodologias ora de maneira isolada (PEP ou SiGOS), ora de maneira híbrida (PEP/SiGOS). O SiGOS não somente possui a mesma ênfase da dinâmica participativa do PEP como também se originou a partir do próprio PEP. O PEP vem se adaptando às novas contingências, inclusive às do desenvolvimento sustentável. A flexibilidade dessas duas metodologias, segundo análises dos pesquisadores envolvidos e dos participantes das oficinas realizadas, não as tornou incompletas. 


\section{FORMULAÇÃO DE ESTRATÉGIAS DE DESENVOLVIMENTO BASEADO NO CONHECIMENTO LOCAL \\ Valdir Fernandes - Carlos Alberto Cioce Sampaio}

Tanto a metodologia PEP como a metodologia SIGOS, quando fundamentadas nos pressupostos participação e conhecimento construído a partir do saber local, conforme se verificou nos casos analisados, constituem-se em princípios de gestão social. Assim, podem se caracterizar como uma alternativa para superar a sobreposição do cálculo de conseqüências puramente econô mico-individuais, no qual apenas a organização proponente do planejamento se beneficia, ao cálculo de conseqüências ecológica e socioeconômica, no qual a comunidade do entorno, incluindo-se a organização proponente, também se beneficia.

O entendimento dessas considerações abre, assim, novos campos de ação dentro das esferas governamental e social. O Estado abre sua atuação para outro ângulo, voltado para a percepção das capacidades e potencialidades locais, a partir de políticas de coordenação e promoção das iniciativas sociais. A ciência, por sua vez, abre a possibilidade de um conhecimento popular, de alguma forma contendo dimensão tácita, que pode se afirmar como conhecimento real baseado na experiência e percepção dos atores locais.

Espera-se que este esforço para integrar linhas de reflexão de investigação e ação sobre participação e conhecimento, construído a partir do saber local, conforme se verificou nos casos analisados, possa ser um aporte substantivo para promover a construção de um novo paradigma desenvolvimentista. Neste trabalho, as pessoas são os protagonistas, que definem seus modos de vida. E fica aqui a sugestão da necessidade de se criarem novas formas de conceber e praticar a política, balizadas na participação direta, que estimulem o protagonismo real das pessoas e a busca de soluções criativas endógenas, distantes dos mecanismos burocráticos e paternalistas que reforçam a verticalidade e a concentração do poder.

\section{NOTA}

Dedicamos este trabalho de pesquisa ao mestre Prof. Joel Souto-Maior Filho, criador da metodologia Planejamento Estratégico Participativo (PEP) e que atualmente é professor titular da Universidade Federal da Paraíba (UFPB), por seu empenho, dedicação e ética como ser humano e pesquisador. 
FORMULAÇÃO DE ESTRATÉGIAS DE DESENVOLVIMENTO BASEADO NO CONHECIMENTO LOCAL

Valdir Fernandes - Carlos Alberto Cioce Sampaio

\section{REFERÊNCIAS BIBLIOGRÁFICAS}

BARBIERI, E. Desenvolver ou preservar o ambiente. Coleção pensar mundo unido. São Paulo: Cidade Nova, 1996.

BRUNSSON, N. Ideas and actions: justification and hypocrisy as alternatives to control. Cahiers $d u$ Centre de Recherche en Gestion, v. 12, p. 7-23, 1994.

CHANLAT, J. F. Sciences sociales et management: plaidoyer pour une anthropologie générale. São Paulo: Presses de L'Úniversité Laval, 1998.

DEMO, P. Participação é conquista. São Paulo: Cortez, 1993.

DOWBOR, L. Introdução ao planejamento municipal. São Paulo: Brasiliense, 1987.

FERNANDES, V.; SANT'ANNA, F. P. Políticas públicas para o desenvolvimento sustentável. In: VI SIMPÓSIO ÍTALO-BRASILEIRO DE ENGENHARIA SANITÁRIA E AMBIENTAL. Vitória, Niterói: Mundo Virtual, 2002.

GODARD, O.; CERON, J. P.; VINAKER, K.; PASSARIS, S. Desarrollo endogeno y diferenciación de espacios de desarrollo. Estudios Territoriales, n. 24, p. 135-147, mai.-ago. 1987.

GOLEMAN, D. Destructive emotions. Colorado: Bantan Books, 2003.

GONDIM, L. Dilemas da participação comunitária. Revista de Administração Municipal, v. 35, n. 187, p. 6-17, 1988.

HOBBES DE MALMESBURY, T. Leviatán. Madrid: Editora Nacional, 1979.

MAX-NEEF, M. Desarrollo a escala humana. Montevidéu: Nordan Comunidad, REDES, 1993. 
MINTZBERG, H. Os 5 pontos da estratégia. In: MINTZBERG, H.; QUINN, J. B. O processo da estratégia. Porto Alegre: Bookman, 2001.

MINTZBERG, H. The strategy concept II: another look at why organizations need strategies. California Management Review, v. 30, n. 1, p. 25-32, fall, 1987.

MORIN, E. Ciência com consciência. Rio de Janeiro: Bertrand, 2000.

PECI, A. Estrutura e ação nas organizações: algumas perspectivas sociológicas. Revista de Administração de Empresas, v. 43, n. 1, p. 24-35, 2003.

PEROTTO, J. P. Organização regional para desenvolver. Florianópolis: Secretaria de Desenvolvimento Urbano e Meio Ambiente, 1996.

POLANY, M. The tacit dimension. Gloucester, MA.: Peter Smith, 1983.

PORTER, M. E. Estratégia competitiva: técnicas para análise de indústrias e da concorrência. Rio de Janeiro: Campus, 1991.

PORTER, M. E. Competição: estratégias competitivas essenciais. Rio de Janeiro: Campus, 1999.

RAMOS, A. G. The new science of organizations. Toronto; Buffalo: University of Toronto Press, 1981.

ROESCH, S. M. A. Projetos de estágio dos cursos de administração. São Paulo: Atlas, 1996.

SACHS, I. Espaços, tempos e estratégias do desenvolvimento. São Paulo: Vértice, 1986.

SAMPAIO, C. A. C. (Coord.). Projeto-piloto de arranjo produtivo turístico local ecodesenvolvimentista em comunidades localizadas em zona costeira. Blumenau, Florianópolis: FURB, UFSC, 2004. 
FORMULAÇÃO DE ESTRATÉGIAS DE DESENVOLVIMENTO BASEADO NO CONHECIMENTO LOCAL

Valdir Fernandes - Carlos Alberto Cioce Sampaio

SAMPAIO, C. A. C. Gestão Organizacional Estratégica para o Desenvolvimento Sustentável. Itajaí: Editora da Univali, 2000a.

SAMPAIO, C. A. C. Planejamento estratégico participativo (PEP) e gestão organizacional estratégica (SiGOS) para a prefeitura municipal de Gaspar (SC). Gaspar: Prefeitura Municipal de Gaspar, $2000 \mathrm{~b}$. Relatório.

SAMPAIO, C. A. C. Uma proposta de um modelo de gestão organizacional estratégica para o desenvolvimento sustentável. Tese (Doutorado em Engenharia de Produção). Centro Tecnológico. Universidade Federal de Santa Catarina, 1999.

SAMPAIO, C. A. C. Planejamento e gestão organizacional para o desenvolvimento sustentável da Associação de Municípios da Região Serrana (Amures). Lages: Associação de Municípios da Região Serrana, 1998. Relatório.

SAMPAIO, C. A. C. Curso de gestão estratégica de arranjos institucionais para o desenvolvimento sustentável. Florianópolis: Cepagro, 1997a. Relatório.

SAMPAIO, C. A. C. Gestão estratégica de arranjos institucionais para o desenvolvimento sustentável no município de São José do Cerrito - SC. Florianópolis: Cepagro, 1997b. Relatório.

SAMPAIO, C. A. C. Planejamento e gestão organizacional para a Federação Catarinense de Municípios (Fecam). 1997. Florianópolis: Secretária Estadual de Desenvolvimento Urbano e Meio Ambiente de Santa Catarina (SDM), 1997c. Relatório.

SAMPAIO, C. A. C. Planejamento e gestão organizacional para a associação de municípios do extremo sul catarinense (Amesc). Araranguá: Associação de Municípios do Extremo Sul Catarinense, 1997d. Relatório.

SAMPAIO, C. A. C. Planejamento e gestão organizacional para a associação de municípios do meio oeste catarinense (Ammoc). Joaçaba: Associação de Municípios do Meio-Oeste Catarinense, 1997e. Relatório. 
FORMULAÇÃO DE ESTRATÉGIAS DE DESENVOLVIMENTO BASEADO NO CONHECIMENTO LOCAL

Valdir Fernandes - Carlos Alberto Cioce Sampaio

SAMPAIO, C. A. C. Arranjos institucionais para o desenvolvimento sustentável local. Revista de Administração Municipal, v. 43, n. 219, p.71-82, abr.-dez. 1996.

SANTOS, B. de S. A crítica da razão indolente: contra o desperdício da experiência. São Paulo: Cortez, 2000.

SCHERER-WARREN, I. Redes de movimentos sociais. São Paulo: Loyola, 1993.

SENGE, P. A quinta disciplina. São Paulo: Best Seller, 2001.

SOUTO-MAIOR, J. Racionalidades: alguns esclarecimentos. Estudos Avançados em Administração, v. 6, n. 2, p. 967-991, 1998.

SOUTO-MAIOR, J. Planejamento estratégico participativo: uma abordagem para o setor público. In: ECONTRO NACIONAL DA ASSOCIAÇÃO NACIONAL DOS PROGRAMAS DE PÓSGRADUAÇÃO E PESQUISA EM ADMINISTRAÇÃO, 18., 1994, v. 3, p. 57-74, Curitiba. Anais. Curitiba: ANPAD, 26-28 set. 1994a.

SOUTO-MAIOR, J. Teoria da racionalidade na administração e na economia. Curso de Mestrado em Administração, Universidade Federal da Paraíba. João Pessoa: Série Documentos para Estudo, n. 1, 1988.

SOUZA FILHO, J. R. Cooperação e participação: novas formas de gestão de políticas públicas para o desenvolvimento regional. In: INSTITUTO CAPITAL SOCIAL DA AMAZÔNIA. O Planejamento a Serviço do Desenvolvimento Sustentável. Disponível em <http://www.capitalsocial.org.br/Pagemf.htm>. Acessado em 10 jun. 2002.

TRAGTEMBERG, M. Uma prática de participação nas coletivizações na Espanha (1936/1939). In: VENOSA, R. (Org.). Participação e participações. São Paulo: Babel Cultural, 1987. 


\section{FORMULAÇÃO DE ESTRATÉGIAS DE DESENVOLVIMENTO BASEADO NO CONHECIMENTO LOCAL \\ Valdir Fernandes - Carlos Alberto Cioce Sampaio}

TUAN, Y. Topofilia: um estudo da percepção, atitudes e valores do meio ambiente. São Paulo; Rio de Janeiro: Difusão Editorial, 1980.

WALL, S. J.; WALL, S. R. Os novos estrategistas: criando líderes em todos os níveis da organização. São Paulo: Futura, 1996.

WEBER, M. The theory of social and economic organization (Part I). London: W. Hodge, 1947.

WILSON, I. The state of strategic planning: what went wrong? What goes rights? Technological Forecasting and Social Change, n. 37, n. 2, p. 103-110, 1990.

\section{Artigo recebido em 09.09.2004. Aprovado em 20.12.2005.}

\section{Valdir Fernandes}

Doutorando no Programa de Pós-Graduação em Engenharia Ambiental (PPGEA) da UFSC.

Interesse de pesquisa nas áreas de gestão ambiental, socioeconomia, economia solidária, desenvolvimento sustentável, racionalidades.

E-mail: valdir@ens.ufsc.br

Endereço: Rua Antônio Schroeder, 865, São José - SC, 88110-400.

\section{Carlos Alberto Cioce Sampaio}

Pós-Doutor em Ecossocioeconomia pela Universidad Austral de Chile (UACH). Doutor em Gestão Organizacional para o Desenvolvimento Sustentável pelo Programa de Pós-Graduação em Engenharia de Produção e Sistemas da UFSC, com estágio sandwich no Centre de Recherches sur le Brésil Contemporain (CRBC) na École des Hautes Etudes en Sciences Sociales (EHESS).

Interesse de pesquisa nas áreas de gestão estratégica, planejamento estratégico, ecossocioeconomia, economia solidária, desenvolvimento sustentável, turismo sustentável, racionalidades.

E-mail: sampaio@furb.br

Endereço: Rua Gabriela Mistral, 263, Ahú, Curitiba - PR, 80540-150. 